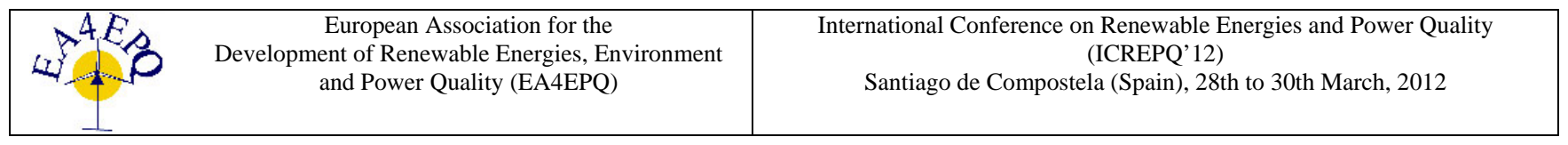

\title{
Electric Field Analysis in Warning Light for Power Lines of High Voltage
}

\author{
J. A. Güemes ${ }^{1}$, A. Iraolagoitia ${ }^{1}$, P. Fernández ${ }^{2}$, and J. Sánchez ${ }^{3}$ \\ ${ }^{1}$ Department of Electrical Engineering \\ ${ }^{2}$ Electronics and Telecommunications Department \\ ${ }^{1,2}$ E.U.I.T.I., University of the Basque Country (UPV/EHU) \\ Plaza de la Casilla 3, 48012 Bilbao (Spain) \\ Phone/Fax number:+0034 946014363 - 4367 - 4502 / +0034 946014300 \\ e-mail: joseantonio.guemes@ehu.es, ana.iraolagoitia@ehu.es, pablo.fernandezr@ehu.es \\ ${ }^{3}$ Research and Development Department, Saprem \\ Ctra. Estella s/n, 31868 Izurdiaga-Izurzun, Spain \\ Phone/Fax number: +0034 948600510 / +0034 948600 560, e-mail: juanjo@saprem.com
}

\begin{abstract}
A method to determine electric field in the surroundings of warning lights for three-phase power lines of high voltage, utilizing finite element method (FEM), is presented in this paper. This work is a preliminary stage in the design process of these devices, in order to define optimum geometry before manufacturing and laboratory test. The results of this research show that electric field is lower when they are used in power line with more than one conductor per phase (bundle of conductors). Laboratory-test results demonstrate the effectiveness of the proposed method to determine electric field distribution and corona inception voltage.
\end{abstract}

\section{Key words}

Corona discharges, corona inception voltage, corona extinction voltage, electric field, finite element method, power lines, warning light.

\section{Introduction}

The conductors suspended in high- and medium-voltage overhead power lines constitute an important danger to aircraft flying at low altitude, when these are located in the neighbourhood of airports. The International Civil Aviation Organization (ICAO) recommends that they should be lighted with beacons installed on the same conductor [1].

The luminous beacons (warning lights for conductor) analyzed in this paper use the field created by the conductor as a power supply. The red warning light is generated by LED technology that can be switched on and off automatically by a twilight sensor [2].

Fig. 1 shows geometry of the warning light for conductor, and its arrangement on the cable to be signalled. Every outer part of the warning light, except the light tube, is made of metal sheet. Inside are the devices required for the warning light's operation.

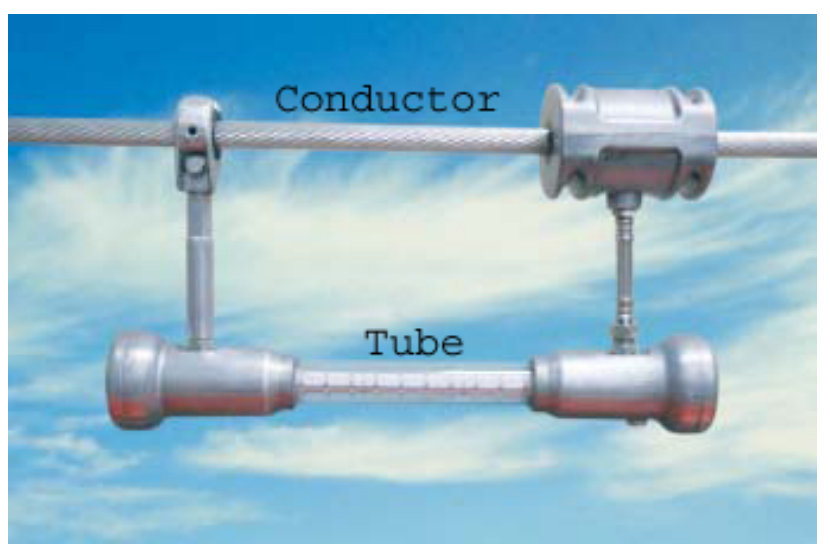

Fig. 1. Warning light for conductor.

Fig. 2 shows a photograph of warning light turned on.

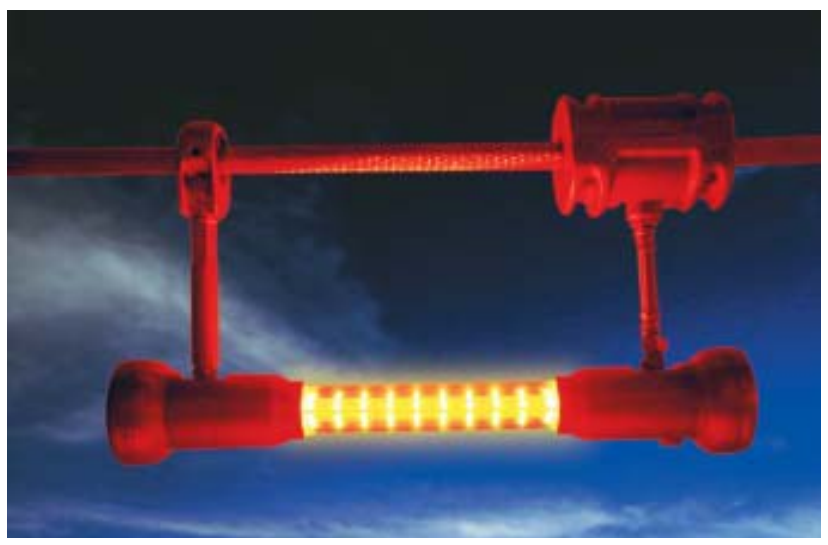

Fig. 2. Warning light turned on.

Previous to industrial manufacturing and marketing, laboratory test of corona effect, also known as corona discharges, must be developed for these devices. The corona effect is caused by ionization of air surrounding a conductor when electric field exceeds a critical value. 
Corona discharges is undesirable in electric power transmission lines, as it produces power loss, audible noise, interference with communication systems, ozone production and insulation damage. Corona effect can be visible in the form of light, typically a purple glow. Darkening of environment where test is carried out helps to visualize the corona effect.

Power lines can be of single or multiple conductors per phase. In this case, they are also called bundle conductors. Bundle conductors consist of several conductors connected by non-conducting spacers. Depending of conductor number, they are also called duplex, triplex, etc., conductors. Bundle conductors are used to reduce corona losses and audible noise.

Corona inception voltage is the lowest voltage at which the corona effect appears as the applied voltage is gradually increased. Corona extinction voltage is the highest voltage at which the corona effect no longer occurs when the applied voltage is gradually decreased from above the corona inception value. Thus, once corona starts, the voltage must be decreased to get it to stop.

During laboratory test, increasing voltage is applied observing when corona effect appears (inception voltage) and then applied voltage is reduced until corona effect disappears (extinction voltage).

As there is no specific standard for test of this type of warning light, corona effect test is carried out according to IEC 61284 standard [3], in section 14, which describes the test method to determine behaviour of fittings in relation to corona effect and radio interference.

Main objective of this work is to simulate laboratory test, according to standard IEC 61284, of warning light for 420 $\mathrm{kV}$ power lines using single and duplex conductors per phase and compare obtained results with those measured during laboratory test.

\section{Formulation}

Electric field follows Maxwell's first equation, also known as Gauss's law for electricity. In case of linear and isotropic media, we have:

$$
\nabla \cdot \boldsymbol{D}=\nabla \cdot[\varepsilon \boldsymbol{E}]=\frac{\partial \boldsymbol{D}_{x}}{\partial x}+\frac{\partial \boldsymbol{D}_{y}}{\partial y}+\frac{\partial \boldsymbol{D}_{z}}{\partial z}=\rho
$$

where $D$ is electric displacement vector and $\rho$ is the charge density per unit volume.

For linear isotropic media:

$$
\boldsymbol{D}=\varepsilon \boldsymbol{E}
$$

where $E$ is electric field and $\varepsilon$ is the electric permittivity.

Taking into account that electric field is irrotational, that is $\nabla \boldsymbol{x} \boldsymbol{E}=\mathbf{0}$ there must be a scalar $U$ that:

$$
\boldsymbol{E}=-\nabla U=-\frac{\partial U}{\partial x} \boldsymbol{i}-\frac{\partial U}{\partial y} \boldsymbol{j}-\frac{\partial U}{\partial z} \boldsymbol{k}
$$

where $U$ is electric potential.

By combination of the equations above, we have Poisson's equation:

$$
\nabla^{2} U=-\frac{\partial^{2} U}{\partial x^{2}}-\frac{\partial^{2} U}{\partial y^{2}}-\frac{\partial^{2} U}{\partial z^{2}}=\frac{\rho}{\varepsilon}
$$

This equation let us calculate electric potential. Once potential is known, electric field can be determined by equation (3).

\section{Model}

Simulation is carried out by FEM, considering air as a solid and discarding electric field variation due to air pressure, temperature or humidity. A 3D model is used and analysis is of electrostatic type.

For FE model to accomplish simulation of warning light's behaviour, the following considerations have to be done:

1) corona effect appears in the surroundings of the warning light, as a consequence, FE model should include this air space;

2) due to device structure, it should be enough for behaviour analysis of warning light to consider only outer surface of metallic parts and apply test voltage. However, as geometry of this device is complex, we have chosen to consider each metallic part as a solid body to ensure that voltage is applied to all surfaces;

3) it is recommended to simplify the geometry of warning light model, without compromising accuracy of the results, in order to make finite element meshing easier and reduce computation time;

4) analyze the symmetry of electric field distribution in order to reduce model volume (node number).

Fig. 3 shows part of the model including the warning 1 ) light, the conductor and the surrounding space of air for power line with single conductor per phase.

Model total volume is a rectangular parallelepiped, whose measures are determined as a function of warning light height to ground-plane when laboratory test is carried out and following IEC 61284 standard at section 14.3. The height above ground of simulated warning light and the separation between conductors of the line using two conductors per phase are the same than dimensions used during laboratory test. In lines using two conductors per phase, the warning light is located on left conductor. 


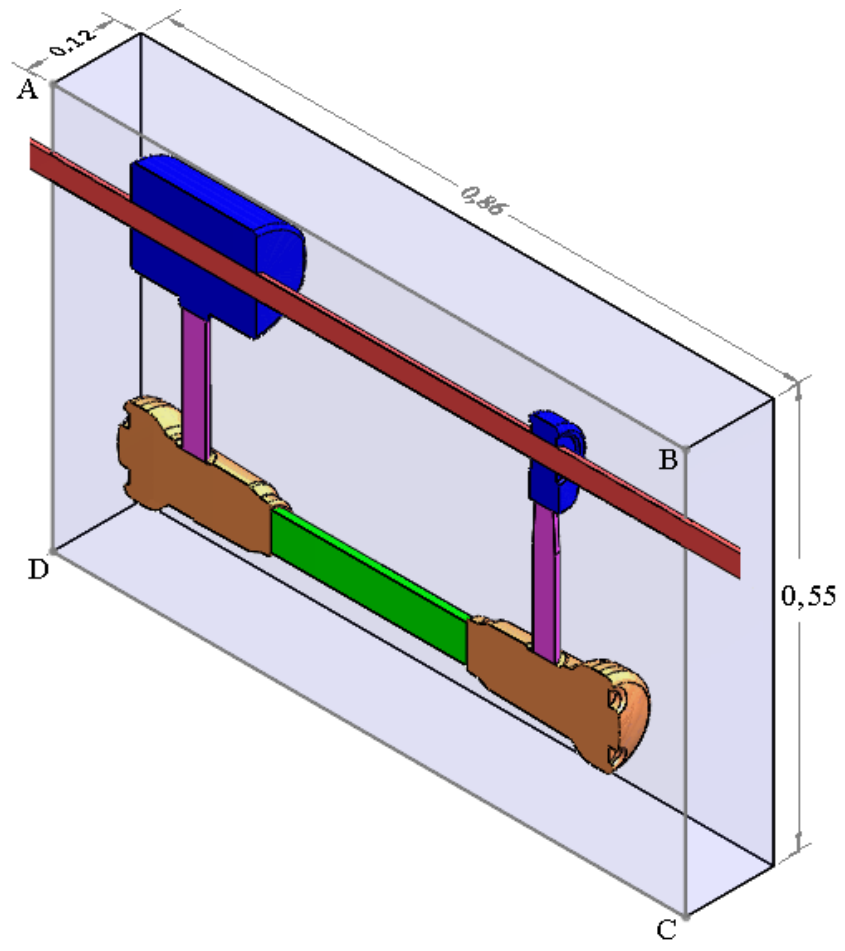

Fig. 3. Warning light and surrounding air model for power lines using single conductor per phase.

Fig. 4 shows the model used to simulate warning light's behaviour for power lines using single and two conductors per phase. In the model for power lines using two conductors per phase, symmetry is not applied.

FE meshing is developed by 3D elements, first order solid tetrahedral. Elements' size is smaller in the areas of higher field variation, namely in the space of air surrounding the curved parts.

Material behaviour is defined by relative permittivity. Excitation and boundary conditions are specified by electric potential.

Implementation has been conveniently realized by using EMS, a commercially available FE package.

\section{Simulations}

In this section is shown: a) electric field distribution calculated when applied phase voltage (voltage line to ground) is $\frac{U}{\sqrt{3}}=\frac{420}{\sqrt{3}}=242.487 \mathrm{kV}$ and b) maximum electric field as a function of applied voltage.

\section{A. Electric field distribution}

Fig. 5 shows the electric field distribution obtained at central plane (ABCD in Fig. 3), once behaviour simulation of warning light has been carried out, for $420 \mathrm{kV}$ power lines using single and two conductors per phase.

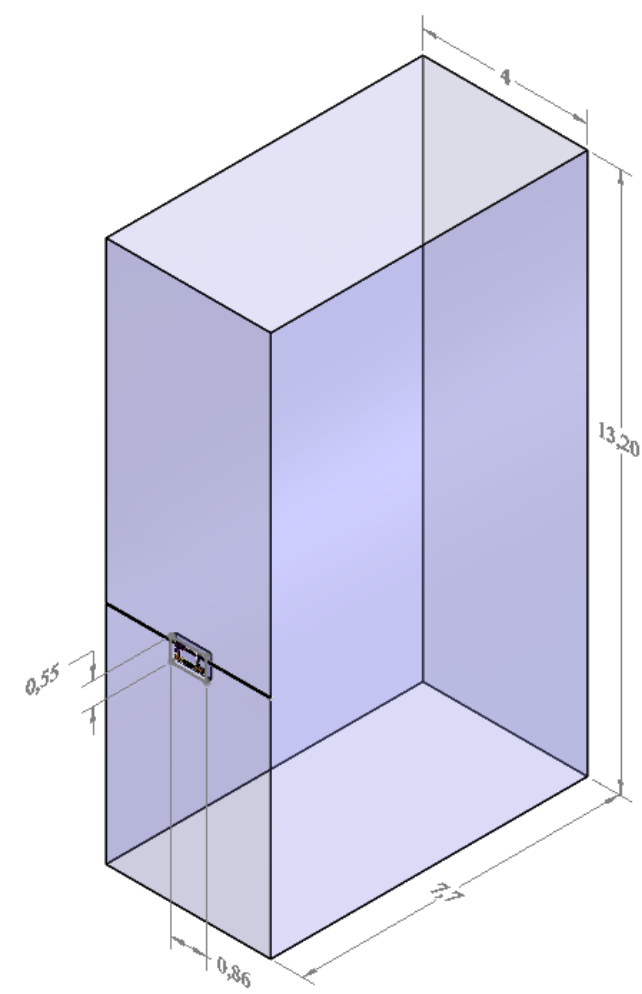

(a) Single conductor per phase.

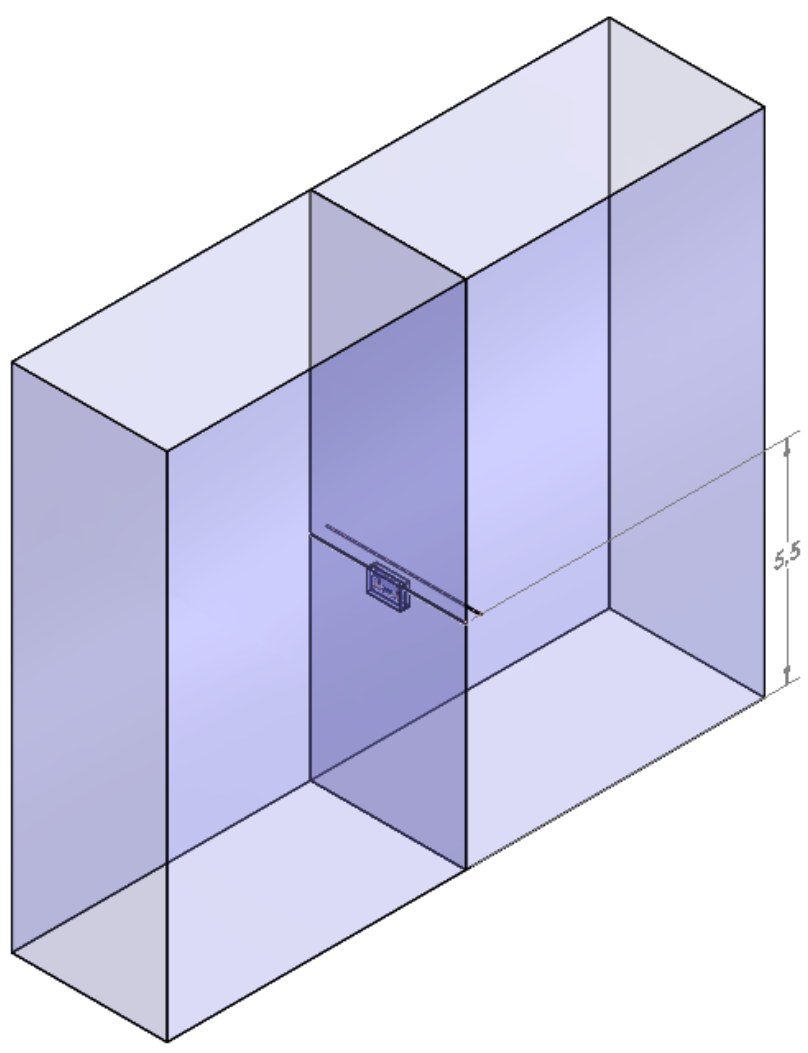

(b) Two conductors per phase.

Fig. 4. Finite element models.

Figure 6 shows the electric field distribution at central plane and air layer near boundary of the warning light. 


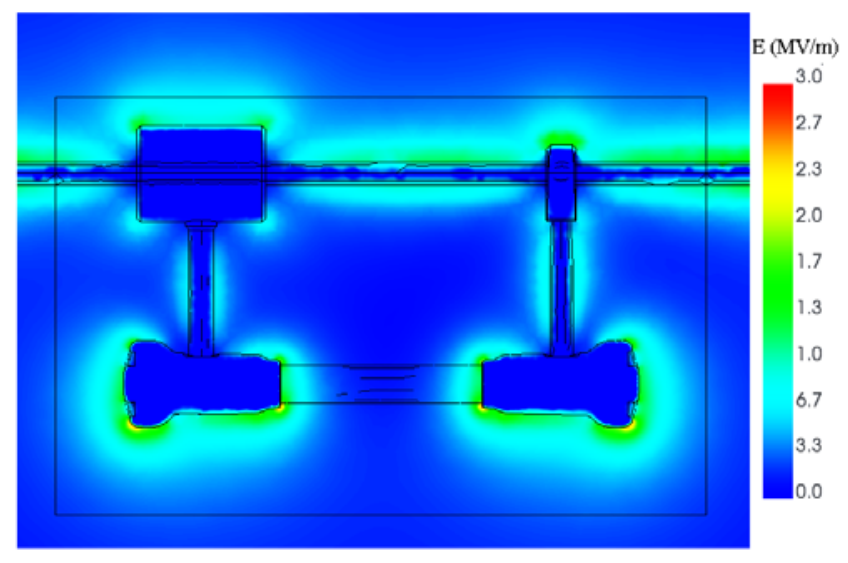

(a) Single conductor per phase.

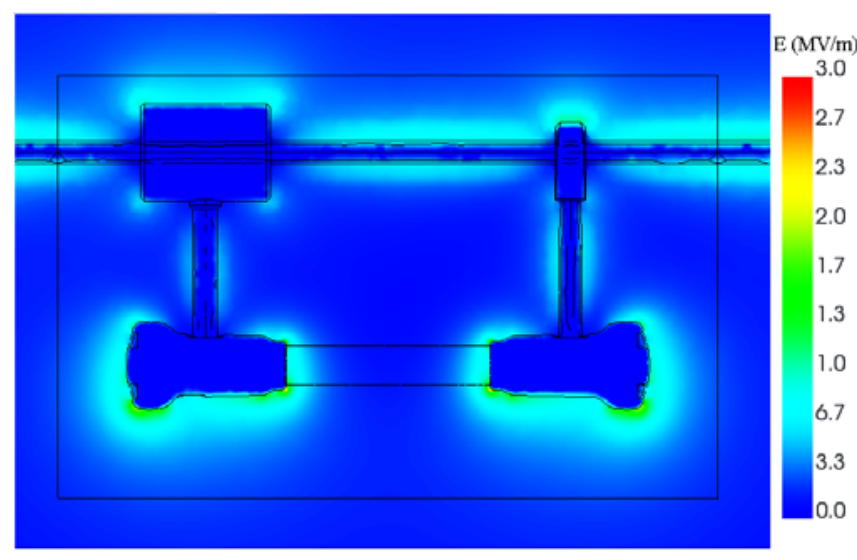

(b) Two conductors per phase.

Fig. 5. Electric field distribution at central plane.

Maximum electric field is obtained at lower sides of the warning light, with values of 2.87 and $2.43 \mathrm{MV} / \mathrm{m}$, respectively, for power lines using single and two conductors per phase.

We can observe that maximum value of electric field is reduced when installing warning light in power lines using two conductors per phase compared to power lines using single conductor per phase.

According to these results, we can think that a method to reduce electric field when warning light is installed at power lines using single conductor per phase could be to place conductors parallel to phase conductor.

\section{B. Corona inception voltage}

Fig 7 shows maximum electric field as a function of voltage per unit (applied voltage divided by the rated phase voltage).

Taking $3 \mathrm{MV} / \mathrm{m}$ as dielectric strength of air, we can determine corona inception voltage. These values are $\frac{1.04}{\sqrt{3}} U=252.7 \mathrm{kV}$ for lines using single conductor per phase and $\frac{1.23}{\sqrt{3}} U=299 \mathrm{kV}$ for the line using two conductors per phase.

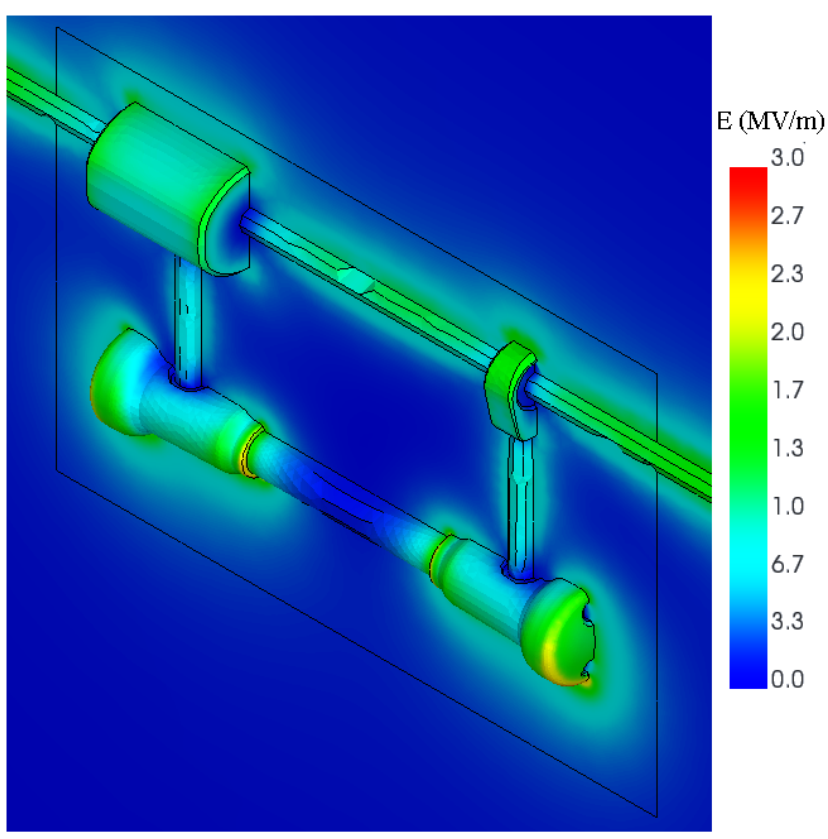

(a) Single conductor per phase.

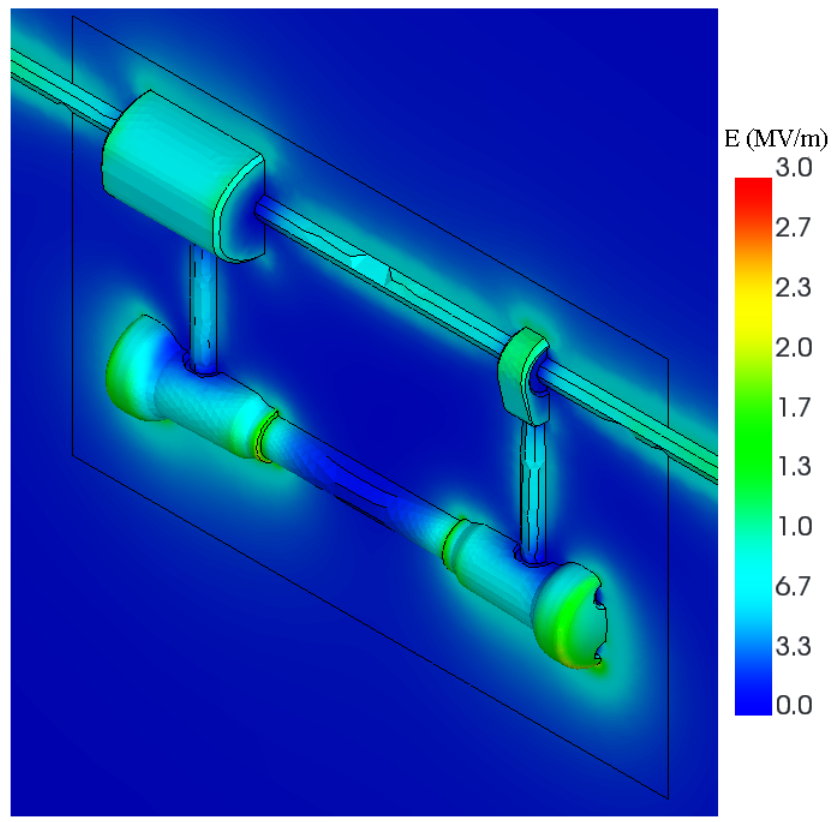

(b) Two conductors per phase.

Fig. 6. Electric field distribution at central plane and air layer near boundary of the warning light.

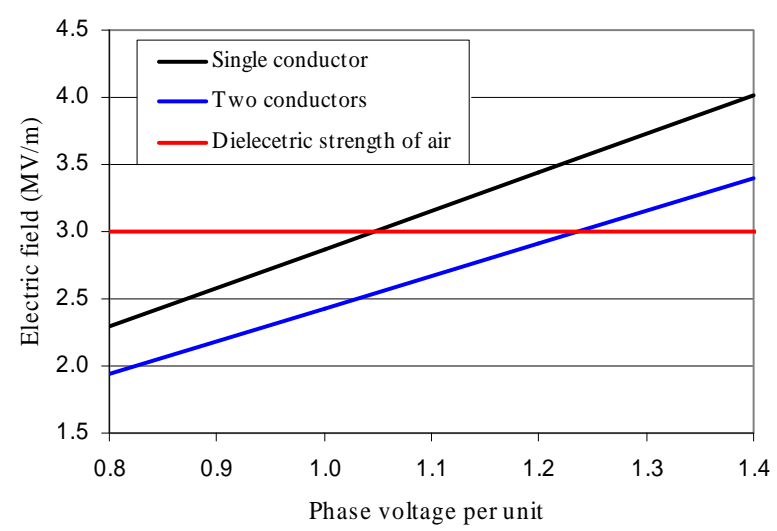

Fig. 7. Maximum electric field versus phase voltage per unit. 


\section{Laboratory test}

Warning light underwent laboratory tests in a power line using two conductors per phase. As conductors, aluminium tubes of $30 \mathrm{~mm}$ of diameter were used. These are located at $5.5 \mathrm{~m}$ height above ground, and a separation of $0.4 \mathrm{~m}$ between them.

Fig. 8 shows a photograph of the assembly made for test of warning light.

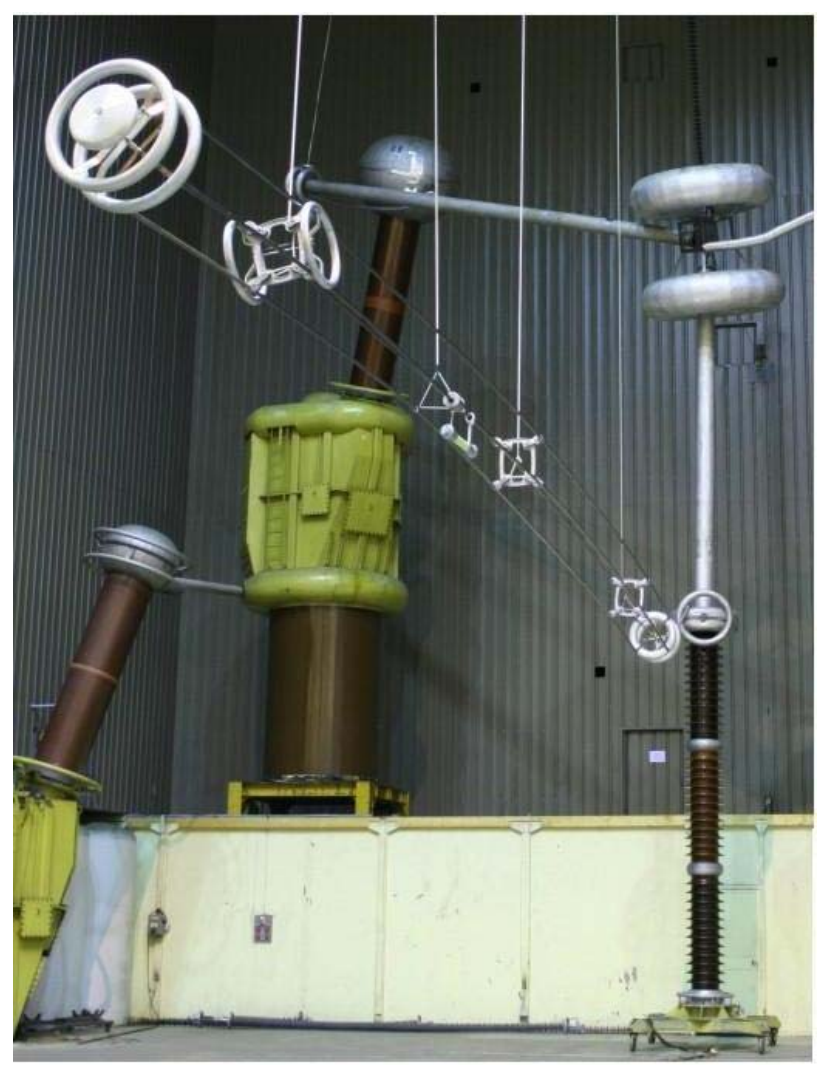

Fig. 8. Laboratory test.

Laboratory test procedure was as follows:

1) keep room in darkness during at least 15 minutes, so that present people grows accustomed to darkness;

2) raise voltage level up to $\frac{1.2}{\sqrt{3}} U=291 \mathrm{kV}$ and keep this level during 5 minutes;

3) step by step reduce voltage to $0 \mathrm{~V}$, writing down voltage levels and presence or not of corona effect. Corona discharge is observed using binoculars.

During laboratory test, no corona effect was observed for any voltage level, and it was assured that no corona effect could be seen for phase voltage of $242.487 \mathrm{kV}$ (line to line voltage of $420 \mathrm{kV}$ ) as it should be expected from Fig. 5a.

After carrying out above described test, applied voltage is gradually increased observing when the corona effect appears (inception voltage) and then voltage is gradually decreased observing when this effect disappears. Developed test shows that the corona inception voltage is
$303 \mathrm{kV}=\frac{1.25}{\sqrt{3}} U$ and the corona extinction voltage is

$298 \mathrm{kV}=\frac{1.23}{\sqrt{3}} U$.

Fig. 9 shows a photograph taken during laboratory test of warning light. Small discharges can be observed at lower side of metal parts at both sides of the tube.

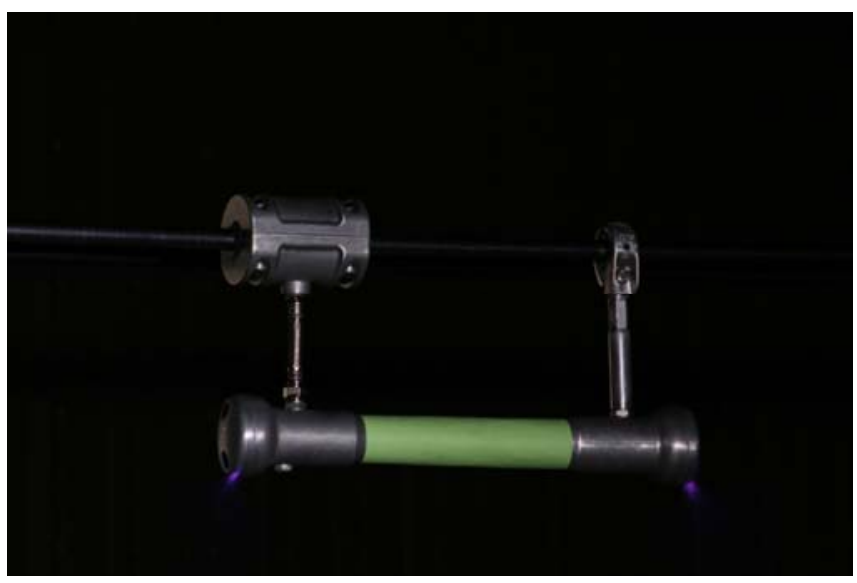

Fig. 9. Corona discharges.

We can observe a good agreement between corona inception voltage calculated by FEM $(299 \mathrm{kV})$ and that obtained in laboratory test (303 kV).

Developed method can help electric engineers to have a better understanding of warning light's behaviour before manufacturing and carry out expensive laboratory tests.

\section{Conclusions}

A methodology, using $\mathrm{FE}$ technique, to determine electric field surrounding warning lights for conductor, has been presented.

Results show an important reduction of electric field for power lines using two conductors per phase compared to that obtained for power lines using single conductor per phase.

Results show an important reduction of electric field for power lines using two conductors per phase, compared to that obtained for power lines using single conductor per phase.

Results obtained by simulation show good concordance with those obtained during laboratory test.

\section{References}

[1] International standards and recommended practices aerodromes. Annex 14 to the convention on international civil aviation, 2004.

[2] htpp://www.saprem.com.

[3] IEC 61284, Overhead lines. Requirements and tests for fittings. 